\title{
MF as Pretreatment of RO for Tertiary Treatment of Biologically Treated Distillery Spentwash
}

\author{
P. Sharma and H. Joshi
}

\begin{abstract}
Biologically treated spentwash from distillery usually contains high chemical oxygen demand (COD), biological oxygen demand (BOD), color, total dissolved solids (TDS) and other contaminants. In India, reverse osmosis (RO) treatment plants have been installed in many of the distilleries at tertiary treatment, but are not properly working due to fouling problem. To make the membrane process proven and reliable technology, proper pre-treatment is mandatory which not only improve quality of RO permeate but also increase life of RO. In the present study, use of micro-filtration (MF) for pre-treatment of RO has been evaluated at the tertiary treatment stage. Experiments were optimized in terms of different operating parameters viz. initial $\mathrm{pH}\left(\mathrm{pH}_{0}: 2-10\right)$, trans-membrane pressure (1-5 bars) and temperature $\left(15-43^{\circ} \mathrm{C}\right)$. Experimental data revealed that the MF could be an effective pre-treatment in removing the pollutants (COD, color and TOC) and improving performance and water recovery (permeate flux) in comparison to RO alone. Removal efficiency for COD, color, TDS and TOC was observed as $31.5 \%, 42.7 \%$ and $27.6 \%$ with $\mathrm{MF}$, respectively at optimized conditions with increased permeate flux from 17.5 LPH (RO) to 32 LPH (MF-RO).
\end{abstract}

Index Terms-Bio-digested distillery spentwash, life cycle assessment, pre-treatment, reverse osmosis, response surface methodology, micro-filtration.

\section{INTRODUCTION}

India is the Asia's second largest ethanol producer with about 2300 million liters annual production in 2006-07 [1]. Indian distilleries mostly come under the major agro-based industry. During the alcohol production, a large amount of the waste water is produced known as "spentwash", which is having high chemical oxygen demand (COD), biological oxygen demand (BOD) and dark brown color. Due to the increasing pressures from environmental regulations authorities, it is essential to treat and reuse their wastewater for achieving zero discharge and proper disposal to avoid damage to environment.

A number of technologies have been researched for treating the distillery spentwash. Biological treatment is generally considered suitable for the effluent having COD/BOD ratio 1.8-1.9 [2]. For high strength of wastewater like distillery spentwash, anaerobic treatment is acceptable and generally practiced in industries. In recent years, investigations have been focused on membrane technology for tertiary wastewater treatment as biological treatment is not able to

Manuscript received April 7, 2015; revised June 10, 2015. This work was supported in part by the India, Department of Science and Technology DST-675-HYD.

The authors are with the Indian Institute of Technology Roorkee, Roorkee 247667, India (e-mail: jangra.pinki@gmail.com, himanshujoshi58@gmail.com). meet the discharge standards alone. In India, reverse osmosis (RO) treatment plants have also been installed in many of the distilleries [3], [4]. Recent work on the pilot scale using a hybrid nano-filtration (NF) and RO process demonstrated 80 to $95 \%$ rejection of the color and $55 \%$ transmission of monovalent salts at pressures of 30-50 atm [5]. Further treatment of the NF permeate using RO at an applied pressure of $50 \mathrm{~atm}$ removed $99 \%$ of the residual salt and produced high quality water containing negligible amounts of salt and organics that was suitable for discharge or industrial reuse. Chang et al. (2006) [6] demonstrated that ceramic ultra-filtration membranes could be used to reject $50 \%$ of the COD of spentwash prior to anaerobic digestion. The key finding of this study was the need for low trans-membrane pressures ( 0.5 atmospheres) and high velocity $(>6 \mathrm{~m} / \mathrm{s})$ to maintain permeability and manage the fouling properties of the molasses.

The results with various membrane systems are promising; however, significant challenges remain in selecting the appropriate pre-treatment system. The organic content in the spentwash after biological treatment is also quite high. Direct application of biologically treated spentwash to RO results in choking of the membrane system and fouling within a short span of time. To make the membrane processes as a proven and reliable technology, improved process designs with providing proper pre-treatment is mandatory [7], [8]. The challenge is to develop suitable pre-treatment systems and selection of the appropriate membrane and system configuration.

This paper discusses the effectiveness of low pressure membrane (MF) as pre-treatment of RO for treating distillery spentwash at tertiary stage. The purpose of the present study is to optimize the MF process as a pretreatment for $\mathrm{RO}$ as the tertiary treatment for the distillery spentwash. The effectiveness of combined MF-RO process using multi-parameter optimization for treating bio-digested distillery spentwash was evaluated.

\section{MATERIALS AND METHODS}

\section{A. Effluent Source and Characterization}

Biologically treated spentwash was collected from a nearby distillery. The characterization of the spentwash for different parameters was done as per standard method of analysis. The main effluent characteristics were: $\mathrm{pH}=8.0-8.3$, $\mathrm{COD}=12000-14000 \mathrm{mg} / \mathrm{l}, \quad \mathrm{BOD}=3500-4000 \quad \mathrm{mg} / \mathrm{l}$ $\mathrm{TSS}=14.5-14.8 \mathrm{~g} / \mathrm{l}$, TDS=8.7-9.0 $\mathrm{g} / \mathrm{l}$ and the color was dark brown. The effluent showed basic nature and having high COD/BOD ratio. 


\section{B. Experimental Setup and Procedure}

MF and RO setup used in the present study was GE SEPA flat plate system with thin film composite membranes. The effective surface area of the membrane was $0.0155 \mathrm{~m}^{2}$. Biologically treated spentwash was used as the feed for MF membrane system whereas, MF treated water sample was taken as the feed for RO system. The operating parameters viz. initial $\mathrm{pH}\left(\mathrm{pH}_{\mathrm{o}}: 2-10\right)$, trans-membrane pressure (1-5 bars) and temperature $\left(15-43^{\circ} \mathrm{C}\right)$ for $\mathrm{MF}$ were used in the experiments. System was optimized using CCD design (discussed later). A Centrifugal pump was used to pump the water into the flat plate membrane module at a controlled pressure with the pressure control valve. Temperature was maintained by running the hot and cold water through the jacketed tank as per the requirement. The $\mathrm{pH}$ of the solutions was adjusted as per the estimated runs by adding $0.1 \mathrm{~N} \mathrm{NaOH}$ or $0.1 \mathrm{~N} \mathrm{H}_{2} \mathrm{SO}_{4}$ solution. Percentage removal of COD, color, TDS and permeate flux was assessed as the system response.

COD, color and TDS of the effluent samples were measured before and after each experiment. TDS and color were measured by double beam UV-visible spectrophotometer (HACH, DR 890, USA). COD was measured using digestion unit (DRB 200, HACH, USA) and UV-visible spectrophotometer (HACH, DR 5000, USA). Percentage removal of these contaminants was calculated by using the following relationship:

$$
\text { Percentage removal }(Y)=100\left(Z_{\mathrm{o}}-Z t\right) / X_{\mathrm{o}}
$$

where, $Z_{\mathrm{o}}$ is the initial concentration of contaminants (COD, color and TDS) and

$Z_{t}$ is the concentration of the contaminants after specified time, $t$.

$$
J=V / A \times t
$$

where, $J$ is permeate flux, $V$ is permeate volume, $A$ is effective membrane area and $\mathrm{t}$ is the time.

Permeate flux $(J)$ is the amount of sample collected per unit area per unit time. It was calculated by dividing the volume of permeate collected $(V)$ divided by the product of effective membrane area $(A)$ and time $(t)$ [9].

\section{Experimental Design}

CCD design of response surface methodology was used for the optimization of the variable parameters based on few sets of experiments. Three factors with five levels have been used for the experimental design. For statistical calculations, the levels were coded as $X_{i}$ according to the following relationship [10]:

$$
X_{i}=\left(X_{i}-X_{\mathrm{o}}\right) / \delta X
$$

where, $X_{\mathrm{o}}$ is value of the $X_{i}$ at the centre point and $\delta X$ presents the step change. The different variables and their levels for MF and RO system are given in Table I.

\section{RESULTS AND DISCUSSION}

\section{A. Optimization of $M F$}

Trans-membrane pressure, temperature and $\mathrm{pH}$ are important factors which affect the performance of the membrane process.

TABLE I: PROCESS VARIABLES AND THEIR LEVELS FOR MF

\begin{tabular}{llccccc}
\hline Variable unit & Factors & \multicolumn{5}{c}{ Level } \\
\hline & $X$ & -2 & -1 & 0 & 1 & 2 \\
\hline Initial $\mathrm{pH}, \mathrm{pH}_{0}$ & $X_{1}$ & 2 & 4 & 6 & 8 & 10 \\
Temperature $\left({ }^{\circ} \mathrm{C}\right)$ & $X_{2}$ & 15 & 22 & 29 & 36 & 46 \\
$\begin{array}{l}\text { Trans-membrane } \\
\text { pressure (bar) }\end{array}$ & $X_{3}$ & 1 & 2 & 3 & 4 & 5
\end{tabular}

MF membrane system was optimized with three operating parameters, initial $\mathrm{pH}, \mathrm{pH}_{\mathrm{o}}(2-10)$; temperature, $\mathrm{T}\left(15-43^{\circ} \mathrm{C}\right)$ and trans-membrane pressure, TMP (2-5 bars). Effect of different operating parameters on permeate flux and contaminant removal (COD, color, and TDS) was studied by conducting different combinations of experiments using CCD design. Actual and predicted flux and percent removal of COD, color and TDS by MF is shown in Table II. To obtain the regression equations from the linear, interactive, quadratic and cubic model, quadratic model was found to be the best for the experimental data.

Final equation in terms of coded factors are as:

$\mathrm{COD}=+31.89-2.34 \times A+2.25 \times B-0.66 \times C-3.90 \times A 2-$

$1.19 \times B 2-3.33 \times C 2+1.75 \times A \times B+1.45 \times A \times C+0.14 \times$ $B \times C$

Color $=+52.26+3.12 \times A+2.78 \times B+7.98 \times C+1.79 \times A 2$ $-2.26 \times B 2+0.15 \times C 2+2.36 \times A \times B+2.56 \times A \times C-1.67$ $\times B \times C$

TDS $=+14.36-1.00 \times A-0.081 \times B+1.08 \times C-1.68 \times A 2$ $-5.00 \times B 2-4.62 \times C 2+0.12 \times A \times B-0.021 \times A \times C$. $7.908 E-004 \times B \times C$

permeate flux $=+59.43+1.62 \times A+0.78 \times B+0.93 \times C$ $1.52 \times A 2-1.27 \times B 2+1.41 \times C 2-1.94 \times A \times B+1.45 \times A \times$ $C+1.84 \times B \times C$

For MF optimization, the value of the regression coefficient and $p$ for different responses is given in Table III. The $F$ values from the analysis of variance results for COD, color, TDS removal and permeate flux are 10.9, 22.9, 8.7, and 3.5 , respectively. The value of $p$ is less than $(<0.0001) 0.05$, which indicates that the model is statistically significant [11]. If value of $F$ is larger and value of ' $p$ ' is smaller, then the terms of coefficient are more significant [12]. The $p$ values of the model for COD, color, TDS removal and for permeate flux are significantly low $(0.004,0.0001,0.0011$ and 0.0367 , respectively), which indicates that the model fits close to the experimental results [13]. The $R^{2}$ values for COD, color, TDS removal and permeate flux are $0.907,0.954,0.887$ and 0.751 , respectively as given in Table III.

ANOVA results for MF system shows that the model chosen explains the factor response interaction correctly. The 
permeate flux and removal efficiency for COD, color and TDS was found to be close to the optimum conditions. The actual and predicted values of responses are shown in Table II. It shows that the residuals for the prediction of each response are minimum, which indicate that the results of ANOVA analysis are acceptable [10], [11].

\section{B. Effect of Various Operating Parameters}

Fig. 1 shows the three-dimensional response surface graphs for all responses with different variables. Performance of the MF membrane is affected by a change in $\mathrm{pH}$.

TABLE II: EXPERIMENTAL DATA AND FITS FOR MF EXPERIMENTS

\begin{tabular}{|c|c|c|c|c|c|c|c|c|c|c|c|}
\hline \multirow[t]{2}{*}{ Run } & \multirow[t]{2}{*}{ pH } & \multirow{2}{*}{$\begin{array}{l}\text { Temp. } \\
\left({ }^{\circ} \mathrm{C}\right)\end{array}$} & \multirow{2}{*}{$\begin{array}{l}\text { Pressure } \\
\text { (bar) }\end{array}$} & \multicolumn{2}{|c|}{ \% COD removal } & \multicolumn{2}{|c|}{$\%$ Color removal } & \multicolumn{2}{|c|}{ \% TDS removal } & \multicolumn{2}{|c|}{ Permeate flux } \\
\hline & & & & actual & predicted & actual & Predicted & Actual & predicted & actual & predicted \\
\hline 1 & 8 & 20 & 1 & 26.04 & 27.56 & 41.77 & 41.32 & 1.09 & 3.16 & 57.29 & 56.08 \\
\hline 2 & 4 & 30 & 3 & 16.45 & 16.47 & 35.68 & 37.71 & 1.06 & 0.95 & 60.00 & 60.28 \\
\hline 3 & 6 & 25 & 1 & 25.58 & 28.28 & 44.94 & 45.48 & 1.19 & 2.76 & 59.61 & 57.83 \\
\hline 4 & 4 & 20 & 3 & 25.94 & 24.20 & 53.22 & 51.33 & 1.45 & 1.03 & 53.42 & 54.29 \\
\hline 5 & 6 & 25 & 2 & 20.42 & 23.06 & 53.63 & 55.49 & 3.78 & 5.37 & 53.42 & 51.35 \\
\hline 6 & 6 & 30 & 2 & 19.58 & 17.78 & 62.70 & 62.12 & 3.47 & 3.08 & 60.77 & 61.36 \\
\hline 7 & 6 & 25 & 2 & 23.47 & 24.35 & 55.06 & 52.99 & 3.68 & 4.97 & 61.94 & 60.46 \\
\hline 8 & 6 & 25 & 2 & 26.68 & 26.07 & 68.65 & 69.07 & 4.05 & 3.16 & 62.71 & 62.73 \\
\hline 9 & 4 & 20 & 1 & 24.41 & 20.99 & 53.13 & 53.17 & 12.32 & 9.65 & 47.45 & 50.12 \\
\hline 10 & 6 & 25 & 2 & 9.10 & 11.62 & 65.66 & 65.65 & 4.15 & 5.63 & 58.06 & 56.59 \\
\hline 11 & 10 & 25 & 2 & 30.82 & 28.45 & 50.08 & 47.22 & 12.62 & 9.45 & 54.97 & 57.38 \\
\hline 12 & 6 & 20 & 2 & 34.18 & 32.95 & 49.78 & 52.78 & 10.84 & 9.29 & 56.58 & 58.94 \\
\hline 13 & 6 & 25 & 2 & 31.70 & 29.21 & 44.67 & 44.43 & 11.78 & 8.66 & 58.06 & 59.91 \\
\hline 14 & 4 & 30 & 1 & 29.02 & 27.90 & 60.00 & 60.38 & 12.43 & 10.82 & 58.84 & 61.77 \\
\hline 15 & 2 & 25 & 2 & 32.04 & 31.89 & 50.67 & 52.26 & 14.21 & 14.36 & 61.94 & 59.43 \\
\hline 16 & 6 & 25 & 3 & 29.37 & 31.89 & 52.00 & 52.26 & 15.33 & 14.36 & 60.00 & 59.43 \\
\hline 17 & 8 & 20 & 3 & 31.19 & 31.89 & 49.98 & 52.26 & 11.78 & 14.36 & 61.81 & 59.43 \\
\hline 18 & 8 & 30 & 3 & 32.88 & 31.89 & 55.33 & 52.26 & 12.80 & 14.36 & 57.68 & 59.43 \\
\hline 19 & 6 & 25 & 2 & 31.81 & 31.89 & 52.00 & 52.26 & 13.83 & 14.36 & 61.94 & 59.43 \\
\hline 20 & 8 & 30 & 1 & 29.56 & 31.89 & 53.75 & 52.26 & 12.34 & 14.36 & 59.23 & 59.43 \\
\hline
\end{tabular}

TABLE III: ANALYSIS OF VARIANCE FOR \%COD, COLOR, TDS REMOVAL AND PERMEATE FLUX BY MF

\begin{tabular}{|c|c|c|c|c|c|c|c|c|c|c|c|c|c|c|c|c|}
\hline \multirow[b]{2}{*}{ Source } & \multicolumn{4}{|c|}{ COD } & \multicolumn{4}{|c|}{ Color } & \multicolumn{4}{|c|}{ TDS } & \multicolumn{4}{|c|}{ Permeate flux } \\
\hline & $\begin{array}{l}\text { Sum of } \\
\text { Square }\end{array}$ & DF & $\begin{array}{l}F \\
\text { Value }\end{array}$ & $P$ value & $\begin{array}{l}\text { Sum of } \\
\text { Square }\end{array}$ & $\mathrm{DF}$ & $\begin{array}{l}F \\
\text { Value }\end{array}$ & $P$ value & $\begin{array}{l}\text { Sum of } \\
\text { Square }\end{array}$ & $\mathrm{DF}$ & $\begin{array}{l}F \\
\text { Value }\end{array}$ & $P$ value & $\begin{array}{l}\text { Sum of } \\
\text { Square }\end{array}$ & DF & $\begin{array}{l}F \\
\text { Value }\end{array}$ & $P$ value \\
\hline Model & 683.5 & 9 & 10.8 & 0.0001 & 1099.1 & 9 & 22.87 & $\begin{array}{l}< \\
0.0001\end{array}$ & 475.36 & 9 & 8.71 & 0.0011 & 200.51 & 9 & 3.35 & 0.0367 \\
\hline Residual & 69.95 & 10 & & & 53.40 & 10 & & & 60.61 & 10 & & & 66.56 & 10 & & \\
\hline Total & 753.48 & 19 & & & 1152.5 & 19 & & & 535.97 & 19 & & & 267.07 & 19 & & \\
\hline R-square & \multicolumn{4}{|c|}{0.9072} & \multicolumn{4}{|c|}{0.9537} & \multicolumn{4}{|c|}{0.8869} & \multicolumn{4}{|c|}{0.7508} \\
\hline
\end{tabular}

At each value of $T$, as the $\mathrm{pH}$ increases, the removal efficiency increases till $\mathrm{pH}$ value reaches 7-8. Further increase in $\mathrm{pH}$ decreases COD removal efficiency. Separation performance of the membrane is affected by a change in $\mathrm{pH}$. The reason may be that the change in $\mathrm{pH}$ affects the hydration and absorption capacity of solution on the membrane [14]. At highly acidic and basic $\mathrm{pH}$, the COD removal is low, whereas the color and TDS removal is high at acidic $\mathrm{pH}$. Permeate flux increases with the increase in $T$ and $\mathrm{pH}$ value. Interaction between $T$ and TMP shows that at each value of $T$, as the value of TMP increases, the COD removal is also increased. Effect of $T$ on TDS removal is not much but as the value of $T$ increases, decrease in TDS removal is observed, because increase in the $T$ results in decreased viscosity and high rate of water passage through the membrane. Solubility of the solute also increases as the $T$ increases, which may result in higher diffusion rate of solute through the membrane [15]. At each value of $T$, increase in $\mathrm{pH}$ results in permeate flux increase. Effect of $T$ on permeate flux is not significant due to the low susceptibility of polyamide membrane to structural variations in response to change in temperature [16].

At each value of $\mathrm{pH}$, as the TMP increases, permeate flux also increases. Removal efficiency of the contaminants increases as the TMP increases to an optimum value of TMP after that it starts decreasing. This may be due to the fact that pressure increases the driving force for the solvent and decreases the osmotic pressure. This results in passage of more amount of water through the membrane and high rate of salt rejection [15].

\section{Optimized Conditions}

Multi-objective optimization of operating parameters of MF system was done using desirability function approach so as to maximize the COD, color and TDS removal efficiencies with maximum permeate flux. The value of operating parameters after examining the response curves was found to be 6.9 for $\mathrm{pH}, 25^{\circ} \mathrm{C}$ for temperature and 2.6 bar for TMP respectively at the optimum condition. The maximum predicted COD, color and TDS removal was $31.5 \%, 42.7 \%$ and $27.6 \%$ respectively, with permeate flux being $63.8 \mathrm{LPH}$. Three ratification experiments were carried out at optimum conditions and the actual values obtained by ratification experiments were within $95 \%$ confidence interval of the predicted value.

\section{MF-RO Combined Treatment at Optimized Conditions}

The performance of the MF-RO system at optimized conditions in terms of percentage removal of COD, color and TDS were $99.2 \%, 99.8 \%$ and $99.2 \%$ respectively, with 
increase in permeate flux from 17.5 liter per hour to 32 liter per hour. Permeate flux versus time curves were analyzed using modified form of Hernia's model [9] to evaluate the flux decline mechanism. Permeate flux profile of RO with and without MF pre-treatment is shown in Fig. 2. Figure shows that the initial flux of MF-RO is almost double of flux with
$\mathrm{RO}$ alone. The flux with RO alone decreases more than MF-RO flux which is more or less steady. This study was conducted for $3 \mathrm{~h}$ to show the effect of pre-treatment on permeate flux. Reduction in flux shows the fouling potential of the wastewater with time.
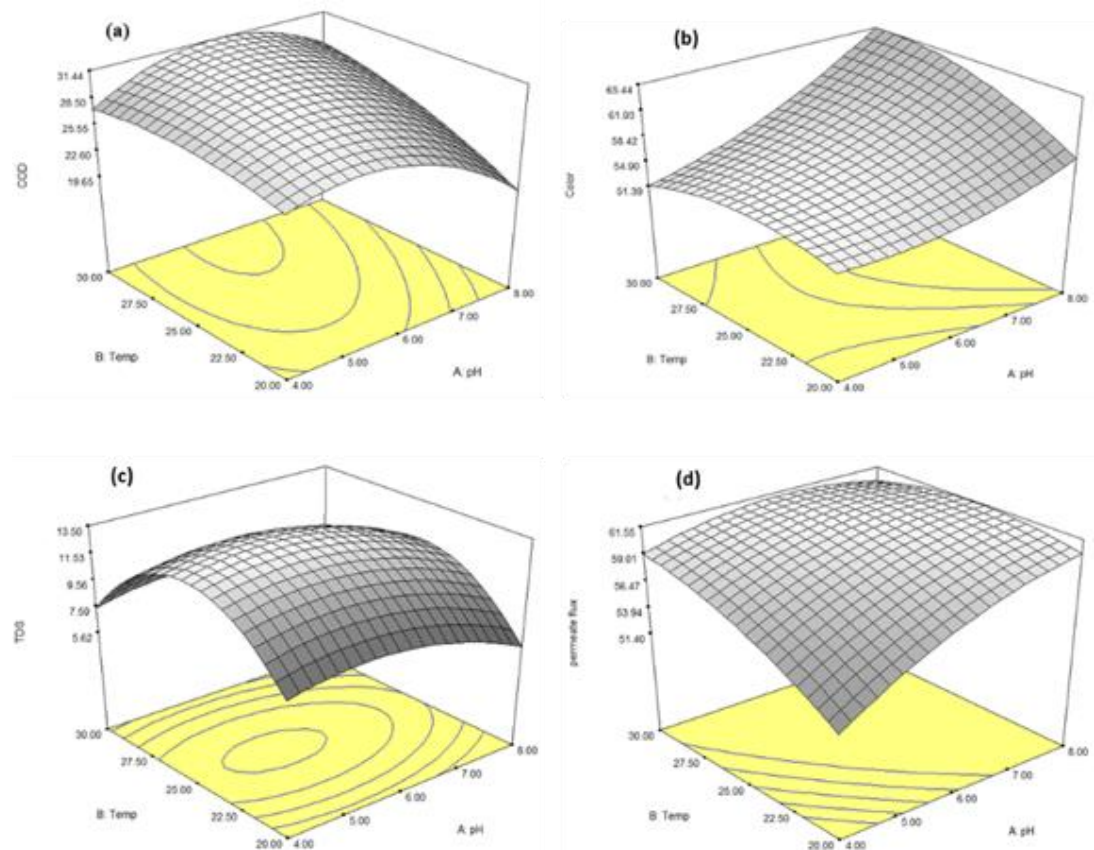

Fig. 1. (i) Effect of $\mathrm{pH}$ and $\mathrm{T}$ on (a) \% COD removal (b) \%color removal (c) \% TOC removal and (d) permeate flux.
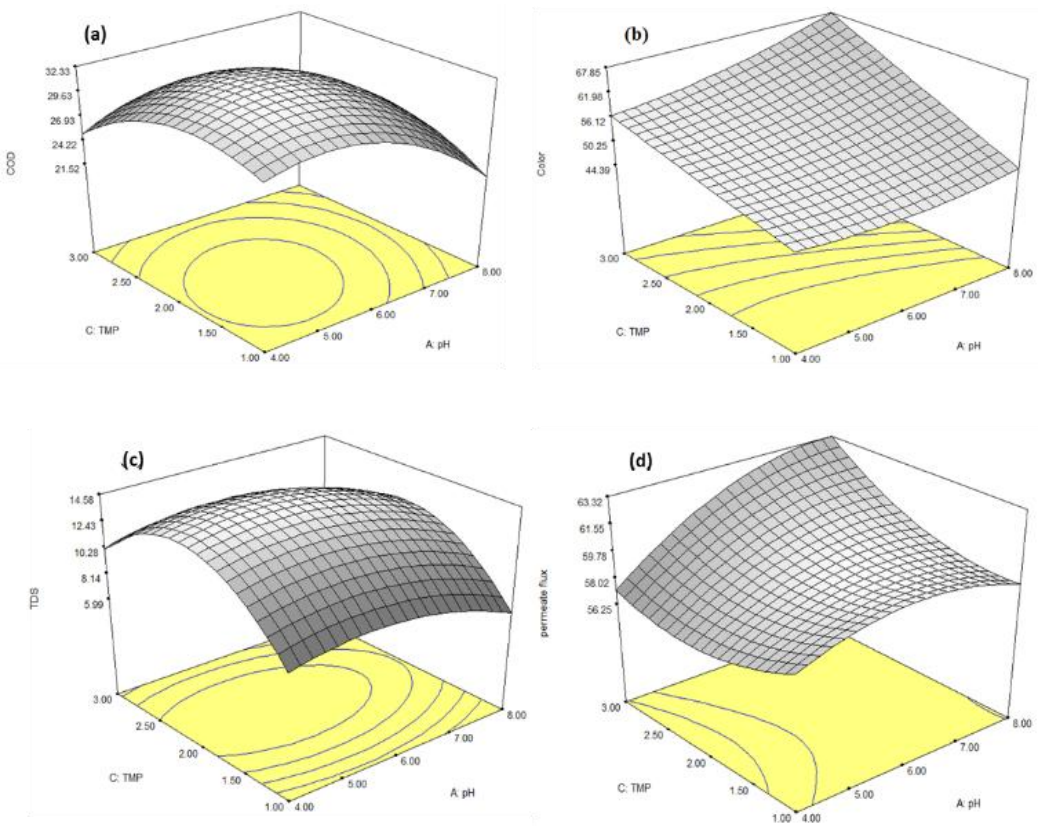

Fig. 1. (ii) Effect of $\mathrm{pH}$ and TMP on (a) \%COD removal (b) \%color removal (c) \% TOC removal and (d) permeate flux.

Permeate flux is a measure of membrane performance and it decreases due to the fouling of the membranes [17]. The best fit model for RO membrane fouling followed the intermediate blocking filtration equation, which assumes that all the particles don't block the membrane pores but settle on other particles [9]. The intermediate blocking filtration model equation is given as:

$$
1 / Q=K_{t} t+1 / Q_{\mathrm{o}}
$$

where, $Q$ is the permeate flow rate, $Q_{\mathrm{o}}$ is initial permeate volume, $t$ is time and $K_{t}$ is the filtration constant.

The permeate flux data was fitted in intermediate blocking filtration model equation to extrapolate the graph and to find out the filtration pattern of RO with and without MF pre-treatment. The study revealed that the MF pre-treatment process doubles the life of the RO system as compared to RO system alone. It also improves the quality of the effluent which can be reused within the industry.

Although adding pretreatment facility adds extra cost to the original setup but it increases water production thereby 
reducing the payback period.

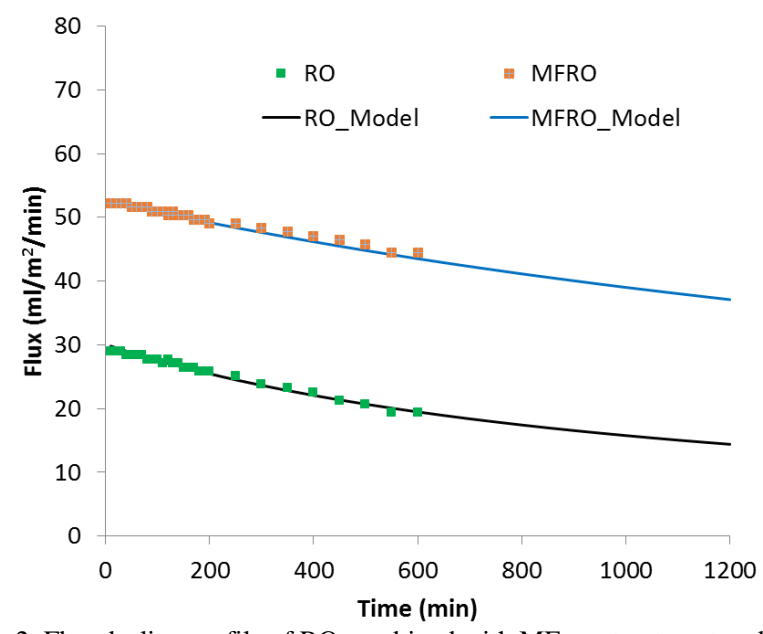

Fig. 2. Flux decline profile of RO combined with MF pre-treatment and RO alone.

\section{CONCLUSION}

Operating parameters and their optimization plays an important role for obtaining maximum treatment efficiency from membrane treatment process. Present study concludes that the MF system seems to be an effective pre-treatment option for RO for the biologically treated distillery spentwash. MF system improves the treatment efficiency of the RO process as well as the life of the RO system. Cost in term of water recovery also gets reduced by using MF-RO compared to $\mathrm{RO}$ alone, as the permeate flux of the RO increases from 17.5 to 32 liter per hour by using MF pre-treatment. Maintenance, cleaning and frequency of membrane replacement also gets reduced and a good quality of permeate can be recovered as resource. MF-RO treatment as a tertiary treatment, hence, is found to be suitable for producing reusable quality of water and meeting the zero discharge standards for distilleries.

\section{ACKNOWLEDGMENT}

Authors would like to thank DST for supporting the research program. Sponsor and financial support acknowledgments are placed in the unnumbered footnote on the first page.

\section{REFERENCES}

[1] K. A. Subramanian, S. K. Singal, M. Saxena, and S. Singhal, "Utilization of liquid biofuels in automotive diesel engines: An Indian perspective," Biomass and Bioenergy, vol. 29, pp. 65-72, 2005.

[2] P. N. Singh, T. Robinson, and D. Singh, "Treatment of industrial effluents-distillery effluent," Bioresource Technology, pp. 135-141, 2004.

[3] Z. V. P. Murthy and L. B. Chaudhari, "Treatment of distillery spentwash by combined UF and RO processes," Global NEST Journal, vol. 11, pp. 235-240, 2009 .
[4] U. K. Rai, M. Muthukrishnan, and B. K. Guha, "Tertiary treatment of distillery wastewater by nanofiltration," Desalination, vol. 230, pp. 70-78, 2008

[5] S. K Nataraj, K. M. Hosamani, and T. M Aminabhavi, "Distillery wastewater treatment by the membrane-based nanofiltration and reverse osmosis processes," Water Research, vol. 40, pp. 2349-2356, 2009.

[6] C. Kwangho et al., "Application of ceramic membrane as a pretreatment digestion of alcohol-distillery wastes* in anaerobic," Journal of Membrane Science, vol. 90, pp. 131-139, 1994.

[7] S. P. Petrova and P. A. Stoychev, "Ultrafiltration purification of waters contaminated with bifunctional reactive dyes," Desalination, vol. 154, pp. 247-252, 2003.

[8] C. Fersi, L. Gzara, and M. Dhahbi, "Flux decline study for textile wastewater treatment by membrane processes," Desalination, vol. 244 pp. 321-332, 2009.

[9] T. Mohammadi, M. Kazemimoghadam, and M. Saadabadi, "Modeling of membrane fouling and flux decline in reverse osmosis during separation of oil in water emulsions," Desalination, vol. 157, pp, 369-375, 2003.

[10] F. I. A. Ponselvan, M. Kumar, J. R. Malviya, V. C. Srivastava, and I. D. Mall, "Electrocoagulation studies on treatment of biodigester effluent using aluminum electrodes," Water, Air Soil Pollut., vol. 199, pp. $371-379,2009$.

[11] C. Thakur, V. C. Srivastava, and I. D. Mall, "Electrochemical treatment of a distillery wastewater: Parametric and residue disposal study," Chem. Eng. J., vol. 148, pp. 496-505, 2009.

[12] J. Segurola, N. S. Allen, M. Edge, and A. M. Mahon, "Design of eutectic photo initiator blends for UV/curable acrylated printing inks and coatings," Prog. Org. Coat., vol. 37, pp. 23-37, 1999.

[13] R. K. Prasad, R. R. Kumar, and S. N. Srivastava, "Design of optimum response surface experiments for electro-coagulation of distillery spent wash,” Water Air Soil Pollut., vol. 191, pp. 5-13, 2008.

[14] D. Berge, H. Gad, I. Khaled, and M. A. Rayan, "An experimental and analytical study of RO desalination plant," Mansoura Engineering Journal, vol. 34, pp. 71-92, 2009.

[15] M. Arora, R. C. Maheshwari, S. K. Jain, and A. Gupta, "Use of membrane technology for potable water production," Desalination, vol. 170, pp. 105-112, 2004.

[16] E. Arkhangelsky, D. Kuzmenko, and V. Gitis, "Impact of chemical cleaning on properties and functioning of polyethersulfone membranes," J. of Membr. Sci., vol. 305, pp. 176-184, 2007.

[17] D. Sun and X. Duan, "Demulsification of water-in-oil emulsion by using porous glass membrane," J. Membr. Sci., vol. 146, p. 65, 1998

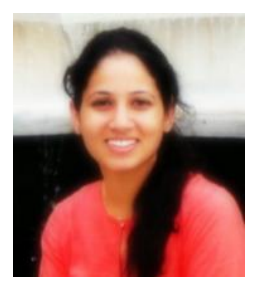

Pinki Sharma was born on March 25, 1985 in India. She got her M.Tech. in 2009 from Environment Engg. Thapar University, Patiala, India and the Ph. D from Hydrology, IIT Roorkee, India. She is now a research scholar in the Department of Hydrology, IIT Roorkee, Roorkee, India. Her research interests are water and wastewater treatment, industrial waste water treatment management, Membrane technology.

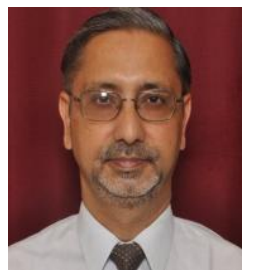

Himanshu Joshi was born on July 26, 1958 in India He got his M.Tech. in 1981 from Civil Engg. (Env. Engg.), I.I.T., Kanpur and the Ph. D in 1995 from Civil Engg. (Env. Engg.), U.O.R., Roorkee. He is now a professor in the Department of Hydrology, IIT Roorkee, Roorkee, India in teaching, research \& consultancy. His research interests are environmental assessment, water, soil and air monitoring, water quality modelling, impact assessment, environmental management, water and wastewater treatment, membrane technology, nanotechnology, phytoremediation, environmental planning, sustainability evaluation, water footprint assessment. 